\title{
PENINGKATAN HASIL BELAJAR PADA PEMBELAJARAN IPS MATERI POKOK JENIS-JENIS PEKERJAAN MELALUI MODEL EXPERIENTAL LEARNING PADA SISWA KELAS III DI SD NEGERI 2 KARANGTALUN KIDUL KECAMATAN PURWOJATI KABUPATEN BANYUMAS TAHUN PELAJARAN 2013/ 2014
}

Oleh:

Sri Praeni

SD Negeri 2 Karangtalun Kidul

\begin{abstract}
ABSTRAK
Penelitian ini dilatar belakangi dari rendahnya hasil belajar siswa kelas III di SD Negeri sidamulya. Adapun tujuannya adalah meningkatkan hasil belajar siswa kelas III di SD Negeri sidamulya dengan menggunakan model experiential learning pada mata pelajaran IPS dengan materi jenis-jenis pekerjaan. Penelitian ini dilakukan 2 siklus. Hasil pra siklus menunjukkan nilai rata-rata 52 dengan persentase ketuntasan siswa $42 \%$, setelah diterapkan model experiential leaning pada siklus I menjadi 66,25 dengan persentase ketuntasan siswa 78\%. Dan pada siklus II menjadi 87 dengan persentase ketuntasan siswa 92\%. Dengan melihat hasil pembelajaran maka dapat disimpulkan bahwa menggunakkan model experiential learning dapat meningkatkan hasil belajar siswa kelas III di SD Negeri sidamulya pada mata pelajaran Ilmu Pengetahuan Sosial materi pokok jenis-jenis pekerjaan.
\end{abstract}

Kata kunci: Hasil belajar, IPS, dan model experiential learning

\section{Pendahuluan}

Berdasarkan observasi dan wawancara yang dilakukandi kelas 3 SD Negeri 2 Karangtalun Kidul, peneliti menemui adanya permasalahan hasil belajar siswa kelas 3 pada awal semester 2 tahun pelajaran 2013/2014 ini, yakni sebanyak 58,33\% siswa belum dapat tuntas KKM pada ulangan harian materi pokok Jenis-jenis Pekerjaan. Hal ini bisa dilihat dari perolehan nilai siswa pada ulangan semester pada tabel 1.1 berikut.

Tabel 1. Data nilai hasil belajar IPS kelas 3 semester 2

\begin{tabular}{|l|l|l|l|l|l|l|l|l|}
\hline \multirow{2}{*}{ No } & \multicolumn{5}{|c|}{ Nilai yang diperoleh } & Jumlah & Tuntas & Belum Tuntas \\
\cline { 2 - 7 } & 9 & 8 & 7 & 6 & 5 & siswa & & \\
\hline 1 & - & - & 4 & 6 & 14 & 24 & 10 & 14 \\
\hline
\end{tabular}

Tabel 1 menunjukkan bahwa nilai rata-rata kelas sudah melebihi KKM, akan tetapi siswa yang belum tuntas KKM masih banyak, yakni 14 siswa dari 24 siswa, atau 58,33\%. Semua siswa seharusnya dapat menuntaskan KKM, akan tetapi hal tersebut belum terwujud. 
Berdasarkan latar belakang masalah di atas dan untuk mempermudah alur pembahasan, maka peneliti merumuskan masalah dalam penelitian ini sebagai berikut:

1. Bagaimana penerapan model pembelajaran experiential learning dalam meningkatkan hasil belajar siswa kelas 3 SD Negeri 2 Karangtalun Kidul dalam pembelajaran IPS materi jenis-jenis pekerjaan?

2. Apakah model pembelajaran experiential learning dapat meningkatkan hasil belajar siswa kelas 3 SD Negeri 2 Karangtalun Kidul dalam pembelajaran IPS materi jenis-jenis pekerjaan?

Berdasarkan rumusan masalah tersebut di atas, maka tujuan penelitian ini adalah:

1. Untuk mengetahui penerapan model pembelajaran experiential learning dalam meningkatkan hasil belajar siswa kelas 3 SD Negeri 2 Karangtalun Kidul dalam pembelajaran IPS materi jenis-jenis pekerjaan.

2. Untuk meningkatkan hasil belajar siswa kelas 3 SD Negeri 2 Karangtalun Kidul dalam pembelajaran IPS materi jenis-jenis pekerjaan melalui model experiential learning.

\section{Kajian Teori}

\section{Hasil Belajar}

Hasil belajar mencerminkan sejauh mana siswa telah dapat mencapai tujuan yang telah ditetapkan di setiap bidang studi. Gambaran hasil belajar siswa bisa dinyatakan dengan angka (0 s.d 10).

\section{Model Pembelajaran Experiential Learning}

Model pembelajaran experiential learning dikembangkan oleh David A. Kolb sekitar awal 1980-an. Model ini menekankan pada sebuah model pembelajaran yang holiostik dalam proses belajar. Dalam experiential learning, pengalaman mempunyai peran sentral dalam proses belajar. Penekanan inilah yang membedakan experiential learning dari teori-teori belajar lainnya. Istilah "experiential" di sini untuk membedakan antara teori belajar kognitif yang cenderung menekankan kognisi lebih daripada afektif, dan teori belajar behavior yang menghilangkan peran pengalaman subjektif dalam proses belajar (Baharudin dan Esa Nur Wahyuni, 2007: 165). Dengan demikian bisa dikatakan model experiential learning adalah suatu model proses belajar mengajar yang mengaktifkan peserta didik untuk membangun pengetahuan dan keterampilan melalui pengalamannya secara langsung (empirisme).

model pembelajaran experiential learning merupakan model pembelajaran yang memperhatikan atau menitik beratkan pada pengalaman yang dialami siswa. Siswa terlibat 
langsung dalam proses belajar dan siswa mengkonstruksi sendiri pengalaman-pengalaman yang didapat sehingga menjadi suatu pengetahuan.

Untuk memperjelas alur pemikiran, berikut ini disajikan bagan alur kerangka berpikir yang mendasari langkah-langkah penelitian.

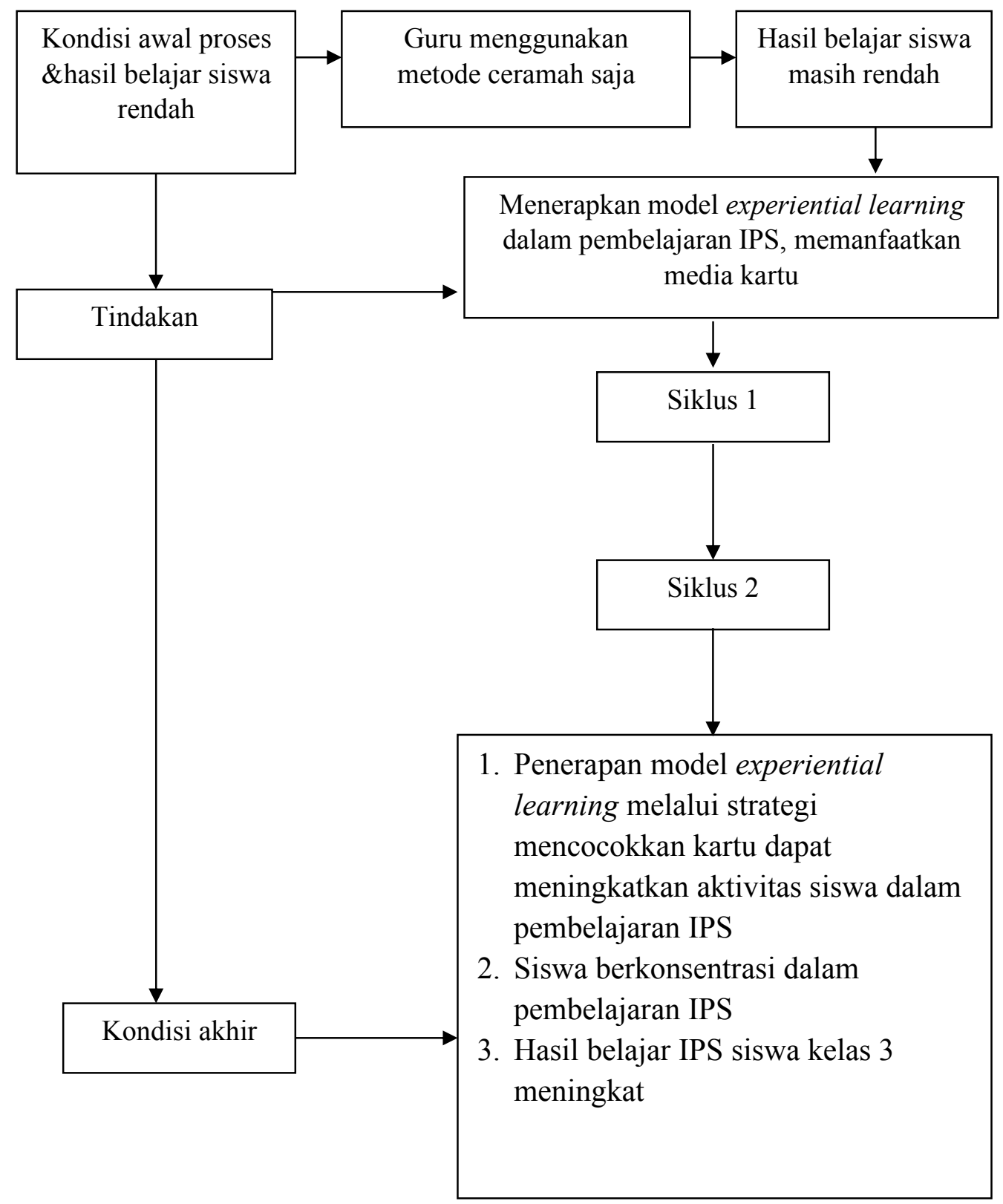

Gambar 1. Alur Kerangka Berpikir Penelitian 


\section{Metode}

\section{Desain Prosedur Perbaikkan Pembelajaran}

Perbaikkan pembelajaran dilaksanakan melalui proses pengkajian berdaur. Yang terdiri dari empat tahap yaitu perencanaan (plan), pelaksanaan (action), mengamati (observation), dan refleksi (reflection).

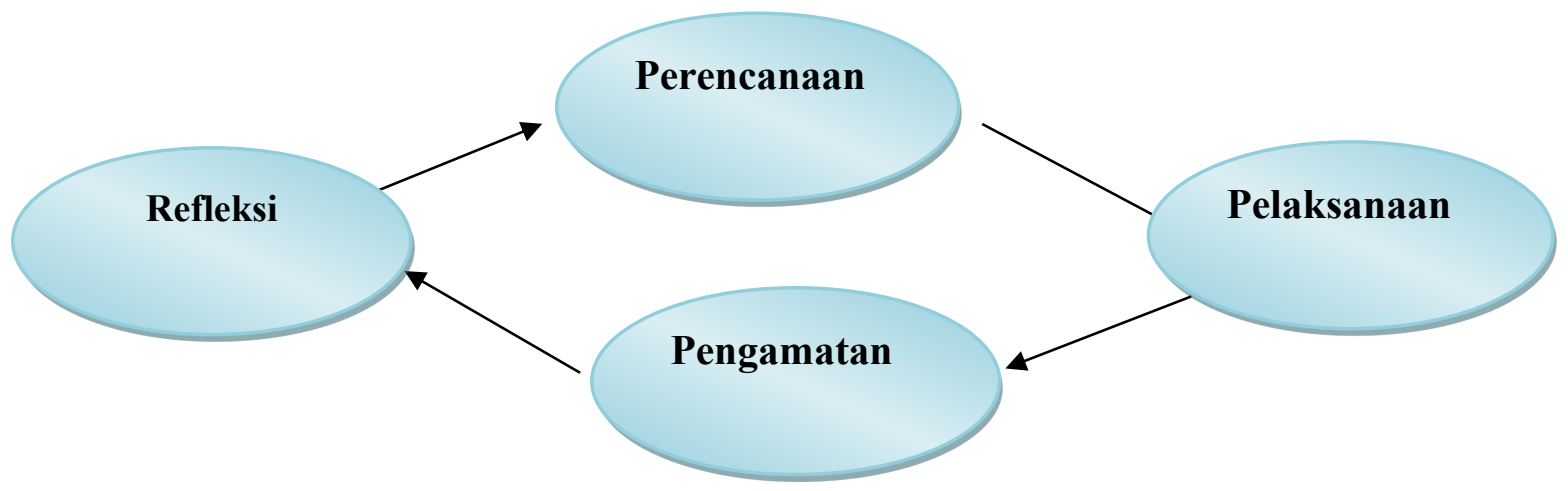

Gambar 2. Tahap-tahap Penelitian Tindakan Kelas

Selanjutnya, adapun langkah-langkah siklus perbaikan pembelajaran sebagaimana pada gambar 3 berikut.

Gambar 3. Diagram Siklus Perbaikkan Pembelajaran

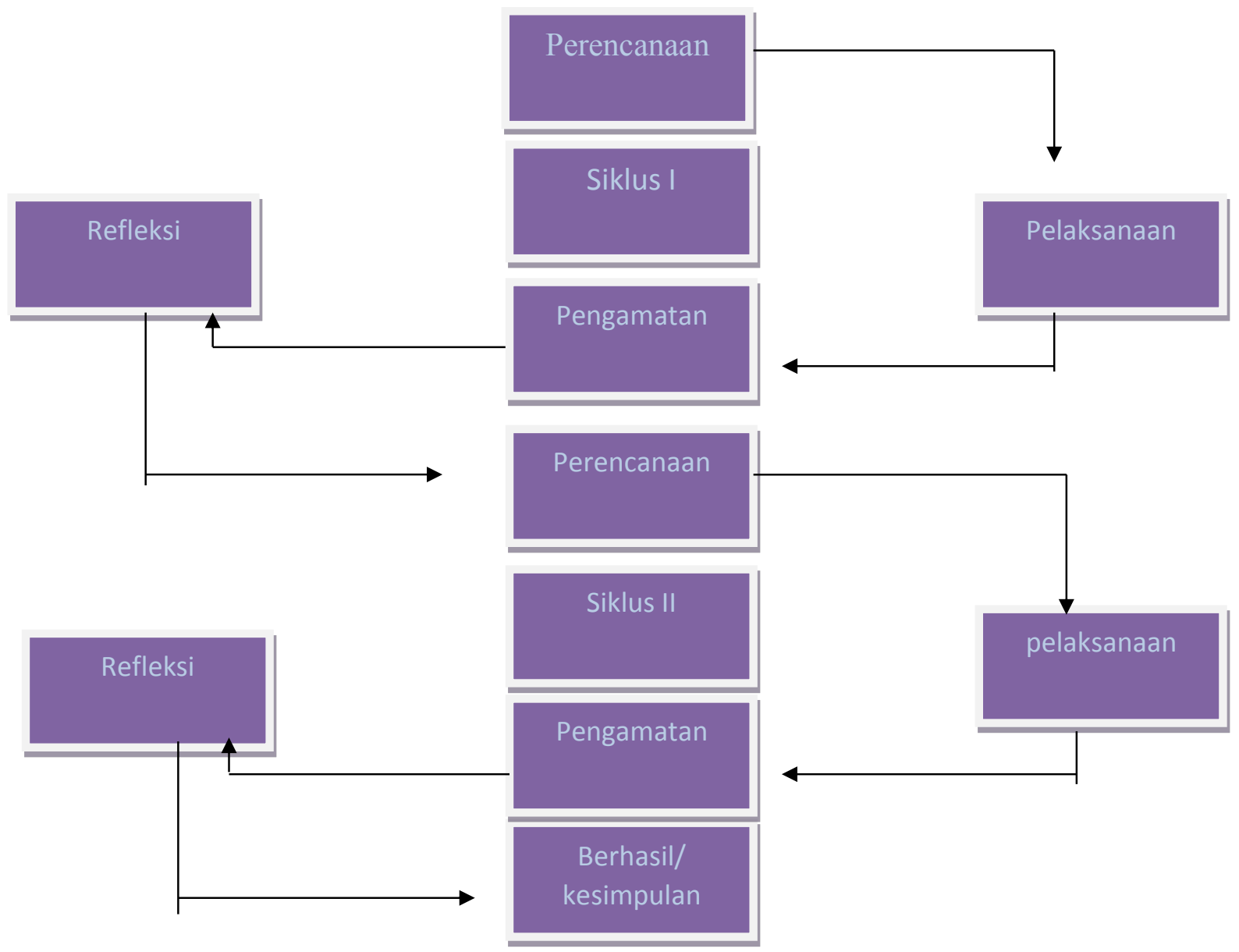




\section{Hasil Penelitian dan Pembahasan}

Berdasarkan hasil pengamatan penelitian dan hasil perolehan nilai pembelajaran siswa pada siklus II menunjukkan peningkatan. Tingkat ketuntasan hasil belajar siswa yang semula pada siklus I 78\% naik menjadi 92\% sedangkan presentase siswa yang belum tuntas yang semula $29 \%$ turun menjadi $8.3 \%$. untuk memperjelas data peneliti menyajikan rekapitulasi ketuntasan siswa dari sebelum perbaikkan sampai siklus I dan Siklus II pada table dibawah ini:

Tabel 2. Tabel Nilai Rata-rata Ulangan pada Studi Awal, Siklus I dan Siklus II

\begin{tabular}{|c|c|c|}
\hline No & Kegiatan & Nilai \\
\hline $\mathbf{1}$ & Studi Awal & 52 \\
\hline $\mathbf{2}$ & Siklus I & 66.25 \\
\hline $\mathbf{3}$ & Siklus II & 87 \\
\hline
\end{tabular}

Dari tabel 2. dapat dibuat diagram batang sebagai berikut:

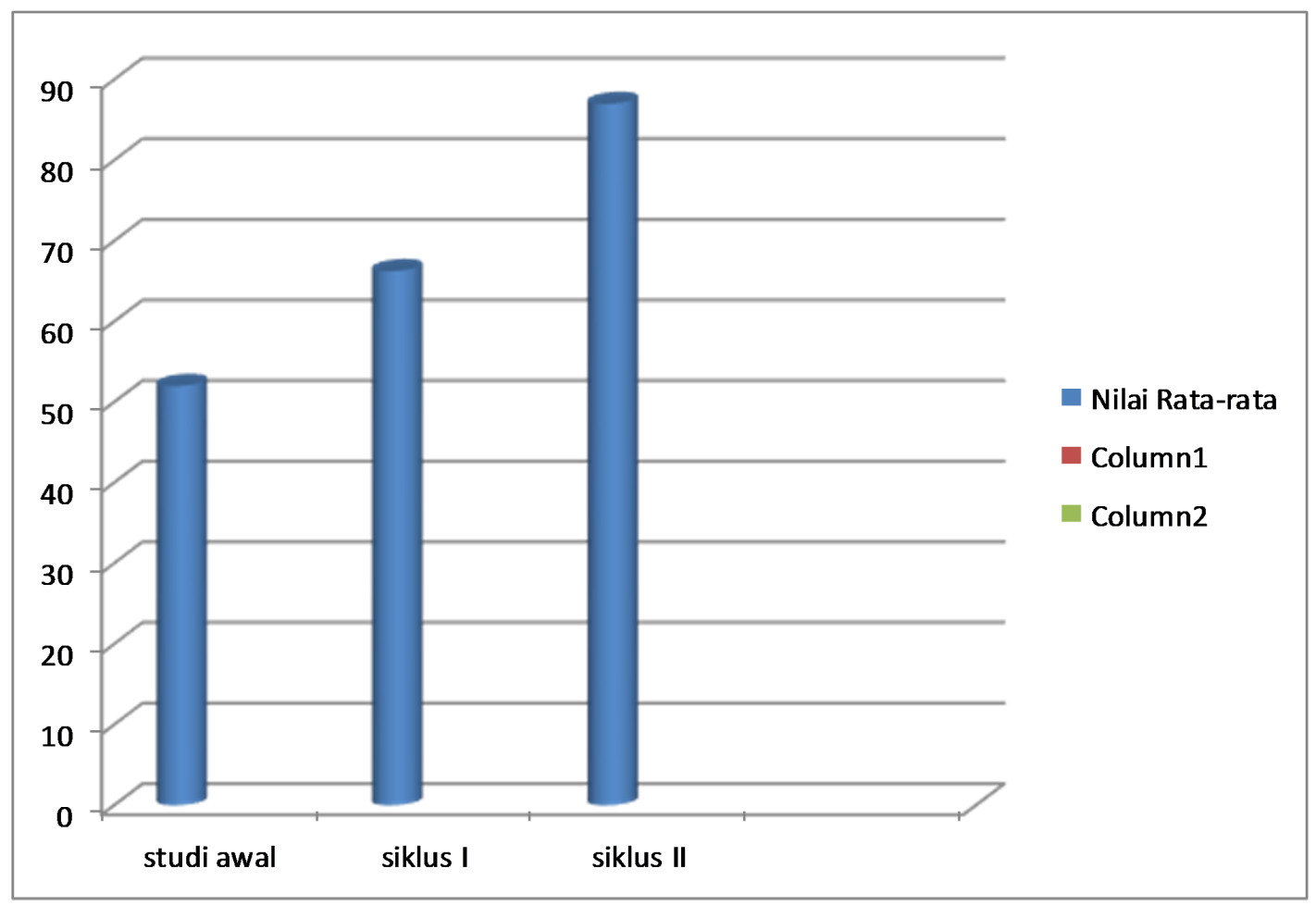

Gambar 4. Diagram Batang Nilai Rata-rata Ulangan IPS pada Studi Awal, Siklus I dan Siklus II.

Dari diagram batang nilai Rata-rata terlihat adanya adanya kenaikkan nilai. Dari studi awal nilai rata-rata 52 pada siklus I 66.25 setelah siklus II nilai mencapai 82. Dengan demikian perbaikkan pembelajaran ini berakhir pada siklus II.

\section{Pembahasan}


Siklus I

Dari hasil temuan dan refleksi selama perbaikkan pembelajaran siklus I,belum mencapai hasil yang memuaskan. Walaupun ada peningkatan jika dilihat dari studi awal. Pada siklus I ketuntasan siswa mencapai 78\% . tindakan dan revisi perbaikkan yang dilakukan memang belum sempurna atau maksimal. Model pembelajaran demonstrasi yang dilakukan oleh peneliti tanpa melibatkan siswa, serta dengan bantuan gambar belum mampu memenuhi criteria ketuntasan yang diinginkan.

Respon siswa terhadap pembelajaran belum maksimal peneliti melakukkan berbagai cara untuk perbaikkan, memancing siswa agar aktif dan focus dalam proses pembelajaraan masih mengalami kendala, peneliti harus berkali-kali mengingatkan siswa atau menunjuk agar mendapatkan respon siswa dalam pembelajaran. Hal ini disebabkan kurangnya variasi peneliti dalam merancang strategi pembelajaran, minimnya alat peraga yang digunakan,selain itu dalam pembagian kelompok masih terlalu banyak siswayang kurang aktif. Presentase keaktifan siswa dalam siklus I mencapai 78\% atau 17 siswa dari 24 siswa. Mengalami kenaikkandari studi awal.

Siklus II

Dari hasil temuan dan refleksi selama siklus II menunjukkan bahwa penerapan metode pembelajaran IPS materi pokok jenis-jenis pekerjaan melalui model experiential learning dengan melibatkan siswa yang dilakukkan dalam pembelajaran ilmu pengetahuan sosial kompetensi dasar menjelaskan bahwa jenis-jenis pekerjaan atau profesi telah ber implikasi baik terhadap pemahaman belajar siswa yan bermuara pada hasil belajar siswa.

Pada siklus II melalui model experiental learning dilakukan peneliti pada kegiatan kelompok yang meliputi penugasan,pengamatan, diskusi, serta bimbingan dari kelompok yang satu ke kelompok yang lain.hal ini menunjukkan tingkat ketuntasan pada siklus II mengalami kenaikkan yaitu siklus I 78\% naik menjadi 92\% . sedangkan nilai rata- rata kelas pada syudi awal 52, siklus I 66.25 dan siklus II 87. Hai ini menunjukkan pembelajaran telah sesuai dengan criteria ketuntasan yang diharapkan peneliti. Dengan demikian peneliti mengakhiri pembelajaran perbaikkan pada siklus II.

\section{Kesimpulan}


Berdasarkan hasil yang diperoleh,penelitimendapatkian suatu kesimpulan tentang manfaat metode pembelajaran melalui model experiental learning yang diterapkan pada pembelajaran ilmu pengetahuan social tentangmateri pokok jenis-jenis pekerjaan yang dapat diamati dalam peristiwa yang terjadi pada kehidupan sehari-hari terbukti dapatmeningkatkan minat dan motivasi belajar IPS siswa.

Dimana pada studi awal siswa tuntas mencapai $42 \%$ nilai rata-rata 52 . setelah adanya perbaikkan pembelajaran dari studi awal ke siklus pertama mencapai $78 \%$ dengan nilai ratarata 66.25. siklus kedua mencapai $92 \%$ dengan nilai rata-rata 87. Peningkatan ketuntasan belajar juga diikuti dengan naiknya minat belajar pada studi awal siswa yang minat ada $35 \%$ pada siklus pertama $42 \%$ dan pada siklus ke dua mencapai $75 \%$. Olehkarena itu, peningkatan minat dan motivasi belajar siswa positif terhadap peningkatan prestasi belajar siswa.

\section{Saran}

Dalam mengimplentasikan hasil kegiatan belajar mengajar dengan menggunakan model experiental learning, maka penulis mengemukakan saran sebagai berikut:

1. Bagi peserta didik

a. Belajar dengan menggunakan metode experiential learning akan menjadikan siswa dalam mengembangkan materi pokok jenis-jenis pekerjaan.

b. Turutilah nasehat orang tua dan guru agar kelak menjadi anak yang berguna bagi nusa bangsa dan agama.

\section{Bagi pendidik}

a. Guru hendaknya dapat menciptakan suasana yang asik dan menyenangkan sehingga anak tidak merasa bosan atau jenuh.

b. Guru sebaiknya menggunakan media pembelajaran yang beragam dan menarik minat peserta didik dalam melaksanakan kegiatan.

c. Guru sebaiknya memberikan penjelasan yang lugas dan jelas kepada peserta didik agar indikator yang ingin diberikan dapat tercapai secara maksimal.

d. Guru sebaiknya memberikan kesempatan untuk bertanya kepada peserta didik agar merasa dhargai dan diperhatikan.

e. Guru sebaiknya memperlakukan peserta didik seperti teman agar tercipta hubungan yang harmonis, menyenangkan dan tidak kaku diantara guru dan anak

f. Guru hendaknya menjalin komunikasi aktif dengan orang tua murid sehingga terjadi keselarasan antara peserta didik di rumah dan disekolah.

3. Bagi orang tua 
a. Orang tua hendaknya selalu mndukung setiap bakat dan minat Anak agar mereka dapat berkembang dengan maksimal.

b. Orang tua hendaknya memahami bahwa perkembangan anak tidak hanya pada lingkup sekolah saja tetapi ada juga dirumah ,perilaku dan sosial emosional yang juga harus diasah pada siswa.

c. Orang tua hendaknya selalu memberikan waktu yang berkualitas bagi anak karena pendidikan anak bertumpu pada orang tua,guru hanyalah sebagai fasilitator.

Sesuai dengan kesimpulan di atas, 1) para guru disarankan agar menerapkan metode melalui model experiential learning untuk meningkatkan hasil belajar siswa pada pembelajaran IPS dengan materi pokok jenis-jenis pekerjaan dalam kehidupan sehari-hari. 2) Sekolah diharapkan selalu memotifasi dan memfasilitasi guru untuk terus meningkatkan kinerjanya untuk membentuk guru yang professional. 3) Dengan adanya penelitian diharapkan siswa lebih aktif dalam merespon pembelajaranyang dilakukan guru, serta menumbuhkan memotifasi dalam belajar.

\section{Daftar Pustaka}

Poerwadarminta,WJS 1995. Kamus Populer Bahasa Indonesia. Jakarta, Gramedia

Djamarah, Syaiful Bahri, 2008. Psikologi Belajar. Jakarta Rineka Cipta.

Slameto. 1999. Belajar Dan Pembelajaran Jakarta, Rineka Cipta.

Purwanto, Ngalim 2005 Psikologi Pendid.ikan Bandung Remaja RosdaKarya.

Wulandari, Sriesti 2000. Psikologi Pendidikkan. Jakarta Rajawali Press.

Nasution, S 1990. Belajar Dan Faktor-Faktor yang Mempengaruhinya. Jakarta Rajawali press.

Surahmad, Winarno 2000. Proses Belajar Mengajar. Jakarta Rineka Cipta.

Kasim, 2008. Pembelajaran IPS Di SD. Jakarta , Balai Pustaka

Yaba,2006. Pelajaran IPS Untuk Sekolah Dasar. Jakarta, Airlangga

Nasution, S 2009. Model Pembelajaran. Jakarta Rineka Cipta.

Baharudi, dkk. 2007. Model-Model Pembelajaran. Jakarta Quantum Teaching.

Silberman, Melvin L 2006. Active Learning. Bandung, Kaifa. 